\title{
A top-down technique to improve the solubility and bioavailability of aceclofenac: in vitro and in vivo studies
}

\author{
Reema Narayan' \\ Abhyuday Pednekar' \\ Dipshikha Bhuyan ${ }^{1,2}$ \\ Chaitra Gowda',3 \\ KB Koteshwara' \\ Usha Yogendra Nayak' \\ 'Department of Pharmaceutics, \\ Manipal College of Pharmaceutical \\ Sciences, Manipal University, Manipal, \\ India; ${ }^{2}$ Lupin Ltd. (Research Park), \\ Pune, Maharashtra, India; ${ }^{3}$ Micro Labs \\ Ltd., Bengaluru, Karnataka, India
}

This article was published in the following Dove Press journal:

International Journal of Nanomedicine

II July 2017

Number of times this article has been viewed
Correspondence: Usha Yogendra Nayak Department of Pharmaceutics, Manipal College of Pharmaceutical Sciences, Manipal University, Manipal 576I04, India Tel +9l 9449207925

$\mathrm{Fax}+9 \mid 820257$ |998

Email usha.nayak@manipal.edu
Abstract: The aim of the present work was to tackle the solubility issue of a biopharmaceutics classification system (BCS)-II drug, aceclofenac. Although a number of attempts to increase the aqueous solubility have been made, none of the methods were taken up for scale-up. Hence size reduction technique by a top-down approach using wet milling process was utilized to improve the solubility and, consequently, the dissolution velocity of aceclofenac. The quality of the final product was ensured by Quality by Design approach wherein the effects of critical material attributes and critical process parameters were assessed on the critical quality attributes (CQAs) of nanocrystals. Box-Behnken design was applied to evaluate these effects on critical quality attributes. The optimized nanocrystals had a particle size of $484.7 \pm 54.12 \mathrm{~nm}$ with a polydispersity index (PDI) of $0.108 \pm 0.009$. The solid state characterization of the formulation revealed that the crystalline nature of the drug was slightly reduced after the milling process. With the reduced particle size, the solubility of the nanocrystals was found to increase in both water and $0.1 \mathrm{~N} \mathrm{HCl}$ when compared with that of unmilled pure aceclofenac. These results were further supported by in vitro release studies of nanocrystals where an appreciable dissolution velocity with $100.07 \% \pm 2.38 \%$ release was observed for aceclofenac nanocrystals compared with $47.66 \% \pm 4.53 \%$ release for pure unmilled aceclofenac at the end of $2 \mathrm{~h}$. The in vivo pharmacokinetic data generated showed a statistically significant increase in the $\mathrm{C}_{\max }$ for aceclofenac nanocrystals of $3.75 \pm 0.28 \mu \mathrm{g} / \mathrm{mL}$ (for pure unmilled aceclofenac $\mathrm{C}_{\max }$ was $1.96 \pm 0.17 \mu \mathrm{g} / \mathrm{mL}$ ). The results obtained indicated that the developed nanocrystals of aceclofenac were successful in improving the solubility, thus the absorption and bioavailability of the drug. Hence, it may be a viable and cost-effective alternative to the current therapy.

Keywords: aceclofenac, nanocrystals, ball milling, QbD, DoE, box-behnken design

\section{Introduction}

Advances such as computer-aided drug design and combinatorial chemistry have been a boon to scientists leading to the discovery of a number of drugs in the recent years. However, the majority of the drugs have high lipophilicity and lower aqueous solubility. About $40 \%$ of the drugs currently in the market belong to the poorly soluble category. This leads to inadequate absorption, requiring larger doses of these drugs to show therapeutic efficacy. The poor solubility is of particular concern for orally administered drugs as it may lead to dose-related toxicities and also increase the cost of drug development. ${ }^{1}$ The drug solubility issue can be a major obstacle in the clinical translational process. As new drug discovery is a costly affair for the pharmaceutical industry, a majority of them are focusing on improving the solubility of the currently marketed drugs by adopting various formulation strategies. ${ }^{2}$ 
Various strategies that have shown improvement in solubility include solid dispersion technique, ${ }^{3,4}$ co-crystals, ${ }^{5,6}$ formation of inclusion complexes, ${ }^{7,8}$ crystal engineering, ${ }^{9}$ size reduction and nanonization, ${ }^{10,11}$ and self-emulsifying drug delivery systems. ${ }^{12,13}$ Of these, nanonization technology is the widely explored and well-established technique for improving the solubility of drugs. There are two approaches for size reduction, namely, bottom-up and top-down approach. In the former approach, controlled precipitation of the drugs is achieved using a suitable non-solvent. Addition of nonsolvent results in super-saturation and nucleation, leading to smaller particles. ${ }^{14}$ The major disadvantage of this method is the presence of residual organic solvents. The latter approach involves size reduction of particles to nano range by using high-pressure homogenization (HPH) or milling techniques. ${ }^{15}$ Of late, another newer technique that is, hot-melt extrusion with HPH is slowly gaining importance. ${ }^{16}$ In the present study, the nanocrystals approach to improve the solubility of a poorly soluble drug aceclofenac (ACF) was attempted using wet milling method by utilizing Quality by Design (QbD) approach.

Drug nanocrystals are crystals of parent compound usually of size $<1 \mu \mathrm{m}$. They are usually composed of $100 \%$ drug without being carriers stabilized with surfactants or steric stabilizers. They are widely accepted because of their advantages over others, that is, they are carrier-free nanoparticles and are easily scalable. A number of approved drug nanocrystals are available in the market like Rapamune ${ }^{\circledR}$ (Pfizer Inc., NY, USA), Emend $^{\circledR}$ (Merck \& Co., Inc., NJ, USA), Tricor ${ }^{\circledR}$ (AbbVie Inc., North Chicago, IL, USA), Megace ${ }^{\circledR}$ (Par Pharmaceutical, Inc., NJ, USA) ES. ${ }^{17-19}$ In spite of the fact that bottom-up process for the production of nanocrystals has greater potential in improving the solubility, and hence bioavailability, due to efficient particle size reduction below $100 \mathrm{~nm}$ and amorphization of the drugs, the currently marketed products have been fabricated by topdown approach. The drawback of this approach is the scale-up problems, wide particle size distribution, and longer processing time. ${ }^{20,21}$ The feasibility of using the top-down approach has been proven by the use of this technology for the production of the commercially available products. Most of these products rely on the use of media milling and HPH approach. ${ }^{16}$ Both these processes carry out size reduction in the liquid suspension form. Hence, careful selection of appropriate type and concentration of stabilizers is the key in the formation of stable nanosuspension. ${ }^{22}$ Out of these two methods, media milling has tremendous potential to produce commercially viable products due to its ease of scale-up that makes the laboratory scale design of nanocrystals valuable. Wet milling technique utilizes ball milling using milling media (glass, zirconium or stainless steel balls). ${ }^{23}$
In the present study, the advantages of wet milling technique using ball mill with milling media were exploited to produce nanocrystals of ACF. Milling is a technique where the coarse particles are broken down into smaller ones by the utilization of mechanical energy. It is one of the easiest ways of producing nanocrystals even on a commercial scale and is highly versatile as any active pharmaceutical ingredient can be processed efficiently. ${ }^{18}$ Literature has reported increased solubility and bioavailability of drugs with particle size reduction by ball milling. ACF is a nonsteroidal anti-inflammatory drug that has poor water solubility, resulting in low bioavailability. It has $\log P$-value of $2.170 .{ }^{24}$ Scientists have worked on improving the solubility of ACF by various approaches like solid dispersion, ${ }^{9,25}$ cyclodextrin complexes, ${ }^{26,27}$ chitosan nanoparticles ${ }^{28}$ and nanocrystals. ${ }^{29,30}$ Recently, Park et al prepared decorated ACF nanocrystals using nanoprecipitation technique. The size was controlled by probe-sonication. ${ }^{29}$ There is another literature on ACF-Soluplus ${ }^{\circledR}$ nanocomposites by high-shear homogenization using a probe sonicator. ${ }^{31}$ Nevertheless, most of these methods use many excipients that may be an economic burden. Also, researchers have used probe-sonication as the tool for size control. Probe sonication induces high energy to the dispersion and reduces the particle size; however, the high energy is not optimal as this may alter the surface characteristics of the drug. The present research work makes use of cost-effective methodology and equipment, that is, ball milling. The nanocrystals produced from ball milling have the additional advantage of up-scaling and down-scaling as per the requirements. In addition, application of QbD will help to reduce the variability that affects product quality and minimize the risk factors. QbD establishes the relationship between the formulation process variables and critical quality attributes (CQAs). Implementation of QbD concepts in drug development will provide high-quality medicines to the consumers at low cost and assures to improve manufacturing quality performance significantly. Accordingly, in the present study, Box-Behnken Design (BBD) was used for constructing the design space. ${ }^{32,33}$ There are number of designs available for designing the experiments such as screening design including full factorial, ${ }^{34}$ Plackett-Burman, ${ }^{35}$ and mixture designs. ${ }^{36} \mathrm{BBD}$ is a response surface design and has advantages of predicting the curvature compared with screening designs, as BBD is a second-order quadratic model for nonlinear responses. While other response designs, including central composite design, require experiments to be performed at 5 levels for each factor, BBD requires 3 levels with lesser number of experimental trials. ${ }^{33}$ 


\section{Materials and methods Materials}

ACF was obtained from Lupin Research Park, Pune, India. Polyvinyl alcohol (PVA) with average molecular weight of 30,000-40,000 g/mol was procured from Sigma-Aldrich, St Louis, MO, USA. All other chemicals used were of analytical or high-performance liquid chromatography (HPLC) grade.

\section{Analysis of ACF}

The amount of ACF present in the formulation and plasma was analyzed by ultraviolet (UV) and HPLC method, respectively. ACF present in the formulation was estimated spectrophotometrically (UV-1601 PC; Shimadzu Corporation, Kyoto, Japan) at a wavelength of $275 \mathrm{~nm}$. ACF in the plasma was quantified using a validated HPLC method (Shimadzu LC-2010HT; Shimadzu Corporation). ${ }^{37}$ A sample quantity of $80 \mu \mathrm{L}$ was injected into the HPLC column (Hypersil BDS $\mathrm{C}_{18}, 5 \mu \mathrm{m}$ ) and maintained at $25^{\circ} \mathrm{C}$, which was eluted out using methanol: $0.3 \%$ triethylamine $\mathrm{pH} 7.0$ $(60: 40 \mathrm{v} / \mathrm{v})$ as mobile phase. The flow rate was maintained at $1.0 \mathrm{~mL} / \mathrm{min}$ and the ACF was detected at $275 \mathrm{~nm}$ using UV detector. Prior to ACF analysis in plasma, the samples were processed and drug was extracted from the same using acetonitrile by protein precipitation method. To $100 \mu \mathrm{L}$ of rat plasma, $25 \mu \mathrm{L}$ of $500 \mu \mathrm{g} / \mathrm{mL}$ concentration of venlafaxine (internal standard) and $200 \mu \mathrm{L}$ of chilled acetonitrile were added and vortexed (Spinix ${ }^{\mathrm{TM}}$ MC-01, Vortex Shaker; Tarsons ${ }^{\circledR}$ Products Pvt. Ltd., Kolkata, India) for $1 \mathrm{~min}$. To this, $675 \mu \mathrm{L}$ of diluent (methanol:water $=80: 20 \mathrm{v} / \mathrm{v}$ ) was added. The above solution was vortexed again to ensure thorough mixing and then centrifuged (3K30; Sigma ${ }^{\circledR}$ Laborzentrifugen, Osterode am Harz, Germany) at $10,000 \mathrm{rpm}$ for $10 \mathrm{~min}$ at $4^{\circ} \mathrm{C}$. The supernatant obtained was injected into HPLC. Both the peaks were found to be resolved with a retention time of $10.208 \mathrm{~min}$ and $18.285 \mathrm{~min}$ for $\mathrm{ACF}$ and venlafaxine, respectively.

\section{Formulation design of nanocrystals by QbD approach}

The nanocrystals of ACF were prepared by adopting the QbD approach. The target product profile (TPP) was set to ensure quality product and is shown in Table 1. Based on the literature available, some of the critical material attributes (CMAs) and critical process parameters (CPPs) were identified that may affect the TPP. The parameters taken into consideration were the milling time, size of balls used, concentration of stabilizer and amount of drug. A risk assessment analysis was performed based on the literature available and the low-risk factors were eliminated from the study. The risk assessment matrix is shown in Table 2. Particle size, polydispersity index (PDI), and zeta potential were chosen as the main risk factors affecting the product performance and for the analysis of CQAs.

\section{Design of experiments (DoE) for optimization of ACF nanocrystals}

DoE is an integral part of $\mathrm{QbD}$ that aids in the planning, optimization and systematic screening of the parameters involved. BBD was used in the present study and particle size $\left(\mathrm{Y}_{1}\right)$, PDI $\left(\mathrm{Y}_{2}\right)$, and zeta potential $\left(\mathrm{Y}_{3}\right)$ were selected as the CQAs. The independent variables taken into consideration were size of balls (A), concentration of stabilizer (B), amount of drug (C), and milling time (D). The speed at which the ball mill rotated was kept constant. The 4 factors were evaluated at 3 levels $(-1,0,+1)$. Numerous experimental designs are available to optimize the formulations that vary based on its applications. In the current study, BBD was selected to study the main as well as interaction effects of the independent variables on the responses. The main aim of the work was to obtain nanocrystals with minimum particle size. BBD is very efficient when the number of factors is more than 3 and to minimize the number of runs as compared with that of central composite design. The values of the coded factors

Table I TPP for the development of nanocrystals of ACF

\begin{tabular}{lll}
\hline TPP elements & Target & Product attributes (CQAs) \\
\hline $\begin{array}{l}\text { Dosage form } \\
\text { Microbial quality }\end{array}$ & Nanocrystals filled in the capsule & Identity, assay, uniformity of content \\
Product performance & No contamination & Test for microbial growth \\
& Robust manufacturing & $\begin{array}{l}\text { Drug content, particle size, PDI, morphology, } \\
\text { solid state characteristics, in vitro drug release }\end{array}$ \\
PK target efficacy & & Pharmacokinetic parameters \\
and safety & Bio-performance: better pharmacokinetic & $\left(C_{\text {max }}, T_{\text {max }}, A U C, M R T\right)$ \\
Stability & profile compared to pure drug & Assay/drug content, redispersibility (measured \\
& Stable for at least 3 months at accelerated & by particle size, PDI) \\
\hline
\end{tabular}

Abbreviations: $A C F$, aceclofenac; $A \cup C$, area under the curve; $C_{\text {max }}$ maximum plasma concentration; $C Q A s$, critical quality attributes; ICH, International Council for Harmonisation of Technical Requirements for Pharmaceuticals for Human Use; MRT, mean residential time; PDI, polydispersity index; PK, pharmacokinetic; $T_{\text {max }}$, time for maximum plasma concentration; TPP, target product profile. 
Table 2 Risk assessment matrix elucidating the effect of CMAs and CPPs on product attributes

\begin{tabular}{|c|c|c|c|c|c|c|}
\hline \multirow[t]{3}{*}{ Drug product's CQAs } & \multicolumn{6}{|c|}{ Risk assessment matrix } \\
\hline & \multicolumn{3}{|l|}{ CMAs } & \multicolumn{3}{|l|}{ CPPs } \\
\hline & $\begin{array}{l}\text { Surfactant } \\
\text { type }\end{array}$ & $\begin{array}{l}\text { Conc of } \\
\text { surfactant (\%) }\end{array}$ & $\begin{array}{l}\text { Amount of } \\
\text { drug (mg) }\end{array}$ & $\begin{array}{l}\text { Milling } \\
\text { time }(h)\end{array}$ & $\begin{array}{l}\text { Ball mill } \\
\text { speed (rpm) }\end{array}$ & $\begin{array}{l}\text { Size of balls } \\
(\mathrm{mm})\end{array}$ \\
\hline Particle size & Medium & Medium & Medium & High & High & High \\
\hline PDI & Medium & High & Medium & High & High & High \\
\hline Zeta potential & High & High & Medium & Medium & Medium & Medium \\
\hline Drug content & Low & Low & Low & Low & Low & Low \\
\hline Rate and extent of release & Medium & Medium & Medium & High & High & High \\
\hline
\end{tabular}

Abbreviations: CMAs, critical material attributes; CPPs, critical product parameters; CQAs, critical quality attributes; PDI, polydispersity index.

for each of the levels are shown in Table 3. The equations were constructed using Design-Expert ${ }^{\circledR}$ software (Trial version 10; Stat-Ease Inc., Minneapolis, MN, USA) and analysis of variance (ANOVA) was used to analyze the model statistically. The experiments were performed in a random fashion as suggested by the software. Based on the results suggested by the software, the optimized batch was prepared again to calculate the relative error and the deviation between the theoretical and practical approach. Three-dimensional response surface plots were designed to clearly identify the effect of variables.

\section{Nanocrystal preparation by wet milling method}

Nanocrystals of ACF were produced by wet milling technique using a ball mill (PM100; Retsch Inc., Newtown, PA, USA). A suspension of ACF in $60 \mathrm{~mL}$ of PVA solution was prepared. In order to ensure homogenous dispersion, the suspension was stirred using a magnetic stirrer for $15 \mathrm{~min}$. The drug suspension was wet milled using preweighed balls $(100 \mathrm{~g})$ at constant milling speed of $400 \mathrm{rpm}$. To evaluate the effect of milling time, size reduction was performed for $1,2.5$, and $4 \mathrm{~h}$. The drug amount was varied between "low" and "high" levels of 200 and $400 \mathrm{mg}$, respectively. Composition of various batches for

Table 3 Variables in Box-Behnken design to form ACF nanocrystals

\begin{tabular}{|c|c|c|c|}
\hline \multirow[t]{2}{*}{ Variables } & \multicolumn{3}{|l|}{ Levels } \\
\hline & -1 & 0 & +1 \\
\hline \multicolumn{4}{|l|}{ Independent } \\
\hline A: Size of balls (mm) & 5 & 10 & 15 \\
\hline B: Conc of stabilizer PVA (\%) & 0.25 & 0.5 & 0.75 \\
\hline C: Amount of drug ACF (mg) & 200 & 300 & 400 \\
\hline D: Milling time $(h)$ & 1 & 2.5 & 4 \\
\hline Dependent & \multicolumn{3}{|l|}{ Constraints } \\
\hline $\mathrm{Y}_{1}:$ Particle size $(\mathrm{nm})$ & \multicolumn{3}{|l|}{ Minimize } \\
\hline$Y_{2}: P D I$ & \multicolumn{3}{|l|}{ Minimize } \\
\hline $\mathrm{Y}_{3}:$ Zeta potential $(\mathrm{mV})$ & \multicolumn{3}{|l|}{ Maximize } \\
\hline
\end{tabular}

Abbreviations: ACF, aceclofenac; PVA, polyvinyl alcohol; PDI, polydispersity index. formulation is given in Table 4. The obtained suspension was then centrifuged (3K30; Sigma Laborzentrifugen) at 22,000 rpm for $15 \mathrm{~min}$ to remove the dispersion medium. The pellets obtained were finally dried at $45^{\circ} \mathrm{C}$ for $24 \mathrm{~h}$ to obtain the nanocrystals of ACF.

\section{Characterization of the nanocrystal formulation}

Mean particle size, PDI and zeta potential

Particle size, size distribution, and zeta potential of the nanocrystals were determined by dynamic light scattering technique using Malvern Zetasizer (ZEN 3600; Malvern Instruments, Malvern, UK) and these were also as a part of process analytical tool. The analysis was carried out in triplicates at $25^{\circ} \mathrm{C} \pm 1{ }^{\circ} \mathrm{C} . .^{88,39}$ The results are presented as mean \pm SD in Table 4 .

\section{Solid-state characterization}

To evaluate the crystalline state of both pure drug and nanocrystal formulation, powder X-ray diffraction (XRD) and differential scanning calorimetric (DSC) studies were performed. XRD pattern was recorded using X-ray diffractomer (X'Pert Powder PAN analytical system, Almelo, the Netherlands) with $\mathrm{Cu}$ Ka radiation generated at $40 \mathrm{~mA}$ and $35 \mathrm{kV}$. Scanning of the samples was performed in the range of $5^{\circ} \mathrm{C}-80^{\circ} \mathrm{C}$. DSC analysis of the samples was performed using DSC 60 Calorimeter (DSC-60 Plus; Shimadzu Corporation). Weighed amount of samples were placed in aluminum sealed pans and heated from $0^{\circ} \mathrm{C}$ to $250^{\circ} \mathrm{C}$ at a heating rate of $10^{\circ} \mathrm{C} / \mathrm{min}$ and under dry nitrogen flow $(30 \mathrm{~mL} / \mathrm{min})$.

\section{Particle morphology}

The morphology of the surface of drug nanocrystals was observed under scanning electron microscope (JSM 50 A; JEOL, Tokyo, Japan). The samples were gold plated with sputter coater, placed on aluminum plates, and observed at an acceleration voltage of $15 \mathrm{kV}$. 
Table 4 Composition and responses of nanocrystals of ACF

\begin{tabular}{|c|c|c|c|c|c|c|c|}
\hline \multirow[t]{2}{*}{ Batches } & \multicolumn{4}{|c|}{ Independent variables } & \multicolumn{3}{|c|}{ Dependent variables } \\
\hline & $A(\mathbf{m m})$ & B (\%) & C (mg) & D (h) & $Y_{1}(\mathrm{~nm})$ & $\mathbf{Y}_{2}$ & $\mathbf{Y}_{3}(\mathrm{mV})$ \\
\hline 1 & 5 & 0.5 & 300 & 1 & $\mathrm{I}, \mathrm{I}, 40 \pm 92.85$ & $0.237 \pm 0.025$ & $-1.65 \pm 0.187$ \\
\hline 2 & 5 & 0.75 & 300 & 2.5 & $874.7 \pm 90.30$ & $0.303 \pm 0.034$ & $-0.754 \pm 0.064$ \\
\hline 3 & 10 & 0.5 & 200 & 4 & $589.9 \pm 43.20$ & $0.267 \pm 0.023$ & $-1.32 \pm 0.143$ \\
\hline 4 & 10 & 0.75 & 300 & 1 & $1,164 \pm 82.0$ & $0.596 \pm 0.063$ & $-1.4 \pm 0.123$ \\
\hline 5 & 10 & 0.25 & 300 & 1 & $615.5 \pm 45.10$ & $0.278 \pm 0.030$ & $-0.305 \pm 0.039$ \\
\hline 6 & 10 & 0.5 & 300 & 2.5 & $689 \pm 67.34$ & $0.304 \pm 0.035$ & $-0.72 \mathrm{I} \pm 0.087$ \\
\hline 7 & 10 & 0.5 & 400 & 4 & $465.2 \pm 27.69$ & $0.358 \pm 0.038$ & $-0.3|4 \pm 0.03|$ \\
\hline 8 & 5 & 0.5 & 300 & 4 & $849 \pm 81.30$ & $0.123 \pm 0.013$ & $-1.19 \pm 0.092$ \\
\hline 9 & 10 & 0.25 & 300 & 4 & $465.8 \pm 20.22$ & $0.298 \pm 0.032$ & $-0.656 \pm 0.068$ \\
\hline 10 & 10 & 0.5 & 300 & 2.5 & $692.3 \pm 35.27$ & $0.209 \pm 0.022$ & $-0.955 \pm 0.112$ \\
\hline 11 & 10 & 0.75 & 300 & 4 & $917 \pm 57.20$ & $0.652 \pm 0.079$ & $-0.967 \pm 0.097$ \\
\hline 12 & 5 & 0.25 & 300 & 2.5 & $543 \pm 49.81$ & $0.318 \pm 0.025$ & $-1.43 \pm 0.153$ \\
\hline 13 & 10 & 0.25 & 400 & 2.5 & $494.6 \pm 50.75$ & $0.348 \pm 0.042$ & $-0.0725 \pm 0.0085$ \\
\hline 14 & 15 & 0.75 & 300 & 2.5 & $603.8 \pm 58.62$ & $0.316 \pm 0.026$ & $-1.01 \pm 0.120$ \\
\hline 15 & 15 & 0.5 & 300 & 1 & $939.3 \pm 103.40$ & $0.568 \pm 0.048$ & $-1.3 \pm 0.138$ \\
\hline 16 & 5 & 0.5 & 200 & 2.5 & $667 \pm 75.48$ & $0.254 \pm 0.019$ & $-0.315 \pm 0.034$ \\
\hline 17 & 10 & 0.5 & 300 & 2.5 & $712.92 \pm 84.74$ & $0.329 \pm 0.034$ & $-1.42 \pm 0.185$ \\
\hline 18 & 15 & 0.25 & 300 & 2.5 & $596.3 \pm 62.30$ & $0.268 \pm 0.029$ & $-1.13 \pm 0.176$ \\
\hline 19 & 15 & 0.5 & 400 & 2.5 & $\mathrm{I}, 050.6 \pm 87.63$ & $1.000 \pm 0.122$ & $-0.789 \pm 0.080$ \\
\hline 20 & 15 & 0.5 & 200 & 2.5 & $598 \pm 64.37$ & $0.179 \pm 0.020$ & $-2.14 \pm 0.182$ \\
\hline 21 & 10 & 0.5 & 300 & 2.5 & $651.1 \pm 78.32$ & $0.308 \pm 0.034$ & $-I .4 I \pm 0.143$ \\
\hline 22 & 10 & 0.75 & 200 & 2.5 & $520.3 \pm 41.64$ & $0.240 \pm 0.019$ & $-1.47 \pm 0.150$ \\
\hline 23 & 10 & 0.75 & 400 & 2.5 & $552.7 \pm 58.32$ & $0.338 \pm 0.039$ & $0.255 \pm 0.023$ \\
\hline 24 & 10 & 0.5 & 200 & 1 & $737.3 \pm 64.11$ & $0.305 \pm 0.027$ & $-1.04 \pm 0.10$ \\
\hline 25 & 5 & 0.5 & 400 & 2.5 & I,I $38 \pm 120.05$ & $0.546 \pm 0.055$ & $-1.6 \pm 0.183$ \\
\hline 26 & 10 & 0.5 & 400 & 1 & $I,|2| . I \pm 98.93$ & $0.278 \pm 0.034$ & $-0.238 \pm 0.026$ \\
\hline 27 & 10 & 0.25 & 200 & 2.5 & $810.6 \pm 82.09$ & $0.312 \pm 0.025$ & $-1.47 \pm 0.172$ \\
\hline 28 & 10 & 0.5 & 300 & 2.5 & $667.8 \pm 58.32$ & $0.32 I \pm 0.028$ & $-1.25 \pm 0.129$ \\
\hline 29 & 10 & 0.5 & 300 & 2.5 & $642.7 \pm 64.80$ & $0.279 \pm 0.029$ & $-1.755 \pm 0.184$ \\
\hline 30 & 15 & 0.5 & 300 & 4 & $732 \pm 70.38$ & $0.515 \pm 0.056$ & $-0.395 \pm 0.046$ \\
\hline 31 & 10 & 0.5 & 300 & 2.5 & $709.9 \pm 89.32$ & $0.459 \pm 0.050$ & $-1.99 \pm 0.159$ \\
\hline 32 & 10 & 0.5 & 300 & 2.5 & $750.1 \pm 60.25$ & $0.323 \pm 0.033$ & $-1.415 \pm 0.128$ \\
\hline
\end{tabular}

Abbreviation: ACF, aceclofenac.

\section{Saturation solubility study of nanocrystals formulation}

Saturation solubility of pure drug and optimized nanocrystals formulation was tested in water and $0.1 \mathrm{~N} \mathrm{HCl}$. An excess amount of unmilled ACF and ACF nanocrystals were added to $10 \mathrm{~mL}$ of each solvent separately and shaken in a water bath shaker for $24 \mathrm{~h}$ at room temperature. The mixture was then filtered using $0.22 \mu \mathrm{m}$ filter and the filtrate was suitably diluted. The absorbance of the solution was measured at $275 \mathrm{~nm}$ using a UV spectrophotometer (UV-1601 PC; Shimadzu Corporation) to determine the solubility of ACF.

\section{In vitro release studies}

In vitro release profile of pure $\mathrm{ACF}$ and $\mathrm{ACF}$ nanocrystals was determined using USP-I apparatus (Electrolab, Mumbai, India). ACF and nanocrystals equivalent to $100 \mathrm{mg}$ of $\mathrm{ACF}$ were filled into separate capsules and carefully placed in the dissolution jar. The release of the drug was studied in $900 \mathrm{~mL}$ of $0.1 \mathrm{~N} \mathrm{HCl}$ containing 2\% Tween 80 maintained at $37^{\circ} \mathrm{C} \pm 0.5^{\circ} \mathrm{C}$ at $75 \mathrm{rpm} .{ }^{28}$ Sample quantities of $5 \mathrm{~mL}$ were withdrawn at predetermined time intervals and equal volume of medium was replaced in the jar to maintain sink conditions. The samples were filtered using $0.22 \mu \mathrm{m}$ filters and analyzed spectrophotometrically (UV-1601 PC; Shimadzu Corporation) at $275 \mathrm{~nm}$.

\section{Pharmacokinetic studies}

The pharmacokinetics of the formulated nanocrystals of ACF was compared with that of pure drug in Wistar albino rats. The animals were maintained at a temperature of $25^{\circ} \mathrm{C} \pm 3^{\circ} \mathrm{C}$ and $60 \% \pm 5 \%$ relative humidity $(\mathrm{RH})$. They were housed in wire cages with free access to feed and water ad libitum. The animals for the study were subjected to overnight fasting. The study was carried out in accordance with The Committee 
for the Purpose of Control and Supervision of Experiments on Animals (CPCSEA) guidelines and the protocol was approved by the Institutional Animal Ethical Committee, Kasturba Medical College, Manipal (IAEC/KMC/07/2017). The animals weighing $200 \pm 8 \mathrm{~g}$ were divided into 2 groups of 6 animals each and treated orally with a dose of $10 \mathrm{mg} / \mathrm{kg}$ as mentioned later in this study. The drug and formulation were dispersed in $0.5 \%$ carboxymethyl cellulose (CMC) before administration. Blood samples were withdrawn periodically at $0.5,1,2,4,6,8$, and $12 \mathrm{~h}$ post-dosing in tubes containing $10 \%$ ethylenediaminetetraacetic acid (EDTA). Plasma was separated by centrifugation (3K30; Sigma Laborzentrifugen) and stored at $-80^{\circ} \mathrm{C}$ until further analysis. The amount of drug in plasma was quantified using HPLC method. The pharmacokinetic parameters $\mathrm{C}_{\max }, \mathrm{T}_{\max }$, area under the curve (AUC), and $\mathrm{Ke}$ were determined by non-compartmental analysis using WinNonlin Software v.5.2 (Pharsight Corporation, Mountain View, CA, USA).

1. Group I - Pure drug p.o.

2. Group II - ACF nanocrystals formulation p.o.

\section{Stability studies}

The developed formulation was subjected to accelerated stability testing as per The International Council for Harmonisation of Technical Requirements for Pharmaceuticals for Human Use $(\mathrm{ICH})$ guidelines at $40^{\circ} \mathrm{C} \pm 2{ }^{\circ} \mathrm{C} / 75 \% \pm 5 \% \mathrm{RH}$ to assess the long-term storage of the formulation. The formulation was placed in United States Pharmacopeia Type-1 flint vials and hermetically sealed with bromobutyl rubber plugs and aluminum caps. The samples were stored in humidity chambers (Thermolab, Mumbai, India) for 90 days and evaluated for particle size and solubility at the end of the study.

\section{Statistical analysis}

The data obtained was expressed as mean \pm SD. Student's $t$-test utilizing GraphPad Prism ${ }^{\circledR}$ (v 1.13) software (La Jolla, CA, USA) was used to compare the different groups. The value of $P<0.05$ was considered as statistically significant. ${ }^{40}$

\section{Results and discussion}

The development of nanocrystals formulation was carried out as per QbD guidelines where the CQAs and CPPs were identified. To assess the effect of material attributes and process parameters on CQAs, DoE was applied to arrive at the optimized formulation. A total of 32 runs as per BBD were generated and the responses obtained are summarized in Table 4. The responses observed were fitted into various models like linear and quadratic using Design-Expert software (Trial version 10; Stat-Ease Inc., MN, USA) to interpret the effects of the factors. The independent variables were identified, and their effect on the dependent variables was analyzed using statistical tools (ANOVA) and three-dimensional (3D) plots. The plots help to study the effect of factors on the responses and also aid in assessing the interaction effect of 2 factors at the same time. The model generated for each of the dependent variables and their influence on the responses is discussed below. The BBD was found to be slightly efficient than other response surface designs but has demonstrated significant efficiency than 3-level full factorial design. Stabilizers play a crucial role in the formulation of nanocrystals. Polymeric stabilizers usually work as steric barriers by getting adsorbed on the particle surface. The surface covering prevents further particle aggregation. Polymers also hinder the collision and growth of particles by accumulating in the hydrodynamic layer between the particles. In the present study, PVA was selected as the stabilizer as it is nonionic, non-toxic and biocompatible. ${ }^{41}$ In addition to this, it has good aqueous solubility, swelling properties and can form an efficient steric barrier preventing particle aggregation. ${ }^{42}$

\section{Effect of independent variables on particle size}

Particle size is the most important factor governing the solubility of nanocrystals thus improving the bioavailability of a drug. The mean particle size of unmilled ACF was $3,428.42 \pm 267.23 \mathrm{~nm}$ and that of nanocrystals was found to be in the range of $465.2 \pm 27.69$ to $1,164 \pm 82.0 \mathrm{~nm}$. BBD suggested a linear model for the effect of particle size. The relationship between the coded factors and particle size was assessed using Equation 1 and 3D plots.

$$
\begin{aligned}
\text { Particle size }= & 740.67-57.64 \mathrm{~A}+92.22 \mathrm{~B} \\
& +74.93 \mathrm{C}-141.53 \mathrm{D}
\end{aligned}
$$

As per the ANOVA results for optimization, a model F-value of 3.52 was obtained, which suggests that the model is significant. There is only $1.94 \%$ chance that model F-value this large could be due to noise. This was further supported by Prob $>$ F-value, which was $<0.05$, indicating that the model terms are significant. Based on the equation, it can be observed that milling time (D) had a profound effect on the particle size $(P<0.05)$. Both milling time (D) and size of balls (A) had negative coefficients whereas the value of coefficients for concentration of PVA (B) and amount of ACF (C) was positive. The negative sign for the coefficient of milling time indicates that the particle size decreases with an increase in the milling time. This can be attributed to the increase in the energy and shear forces produced 
due to impact between the grinding balls and the drug that provides high energy to break the microparticles to nanosized particles. ${ }^{15}$ The positive sign of coefficients for the concentration of PVA and amount of ACF indicates that the particle size increases as the value of the variables increases. The effect of the parameters is clearly observed in the 3D plots shown in Figure 1A-F. As per the reports, an increase in the PVA concentration increases the particle size due to the increased viscosity of the dispersion medium, resulting in decreased attrition between balls and particles and also leading to greater amount of coating on the particle surface. ${ }^{43-46}$ The increase in the amount of ACF was found to increase the particle size. This could be possibly due to the increased amount of drug in the dispersed phase that
A

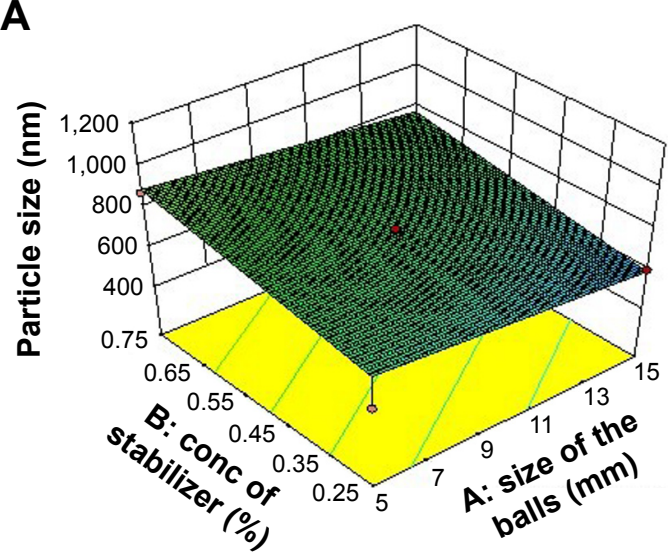

C

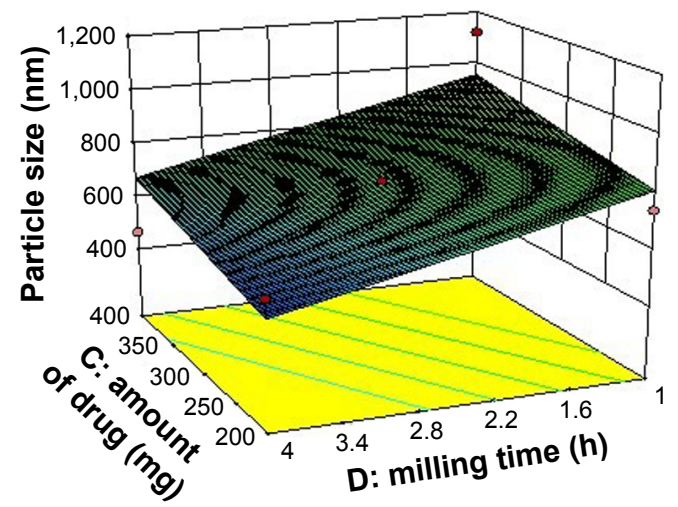

$\mathbf{E}$

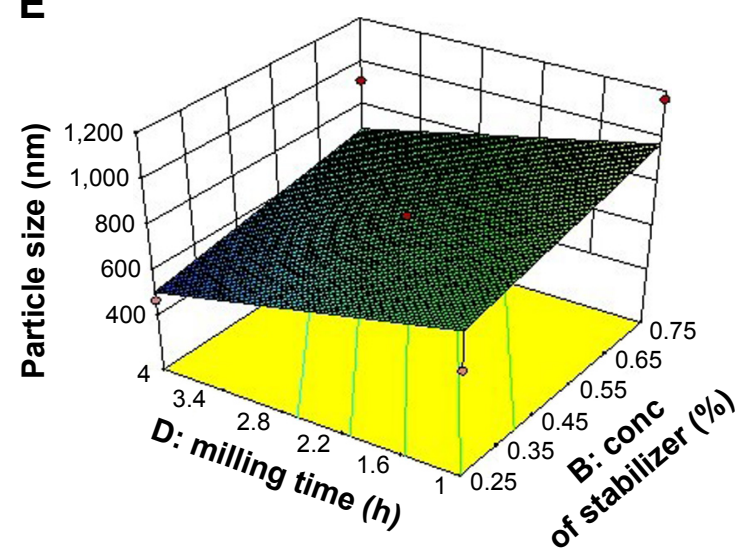

B

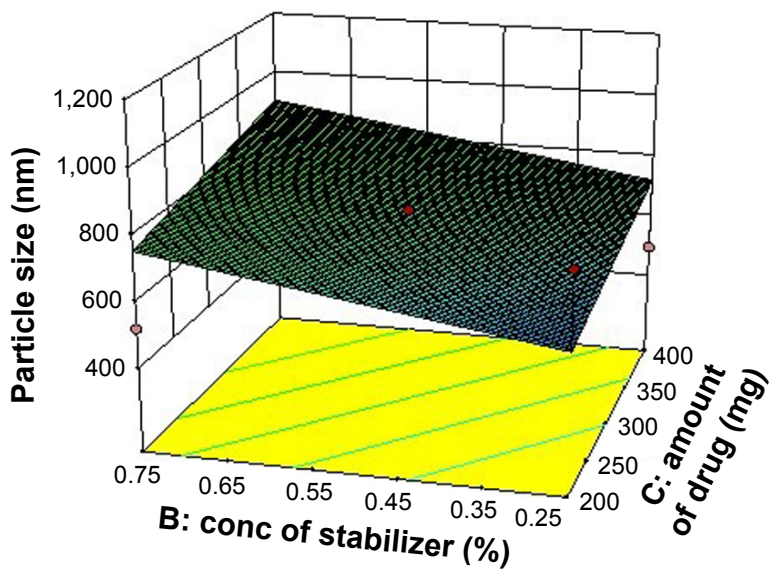

D

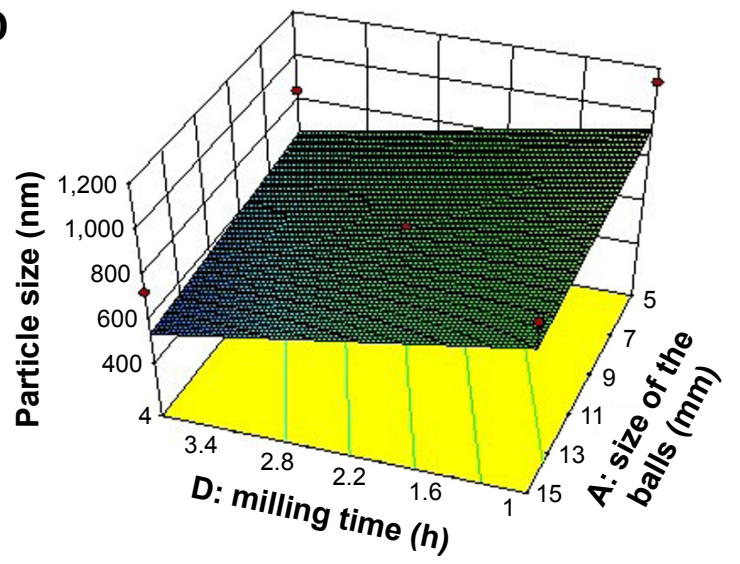

F

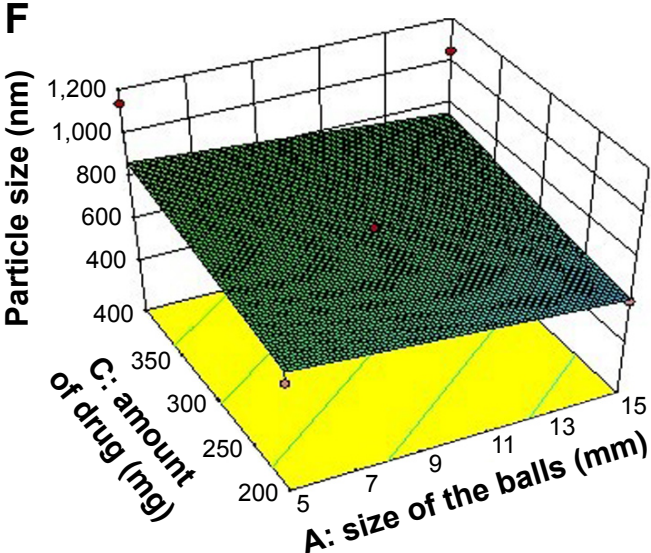

Figure I Three-dimensional plots showing the effect of independent variables on particle size.

Notes: (A) Effect of concentration of stabilizer and size of the balls on particle size; (B) Effect of concentration of stabilizer and amount of drug on particle size; (C) Effect of amount of drug and milling time on particle size; (D) Effect of milling time and size of the balls on particle size; (E) Effect of milling time and concentration of stabilizer on particle size; (F) Effect of amount of drug and size of the balls on particle size.

Abbreviation: conc, concentration. 
results in inefficient particle size reduction. ${ }^{47}$ The larger the size of the balls, the greater is the contact between the drug particles and the balls, leading to better attrition between the two. Hence better size reduction with smaller size particles can be obtained. ${ }^{48}$ In the present work, similar results were obtained on varying the size of the grinding balls.

\section{Effect of independent variables on PDI}

The PDI value ranging from 0.123 to 0.65 supported the presence of homogeneous and narrow particle size distribution. One of the batches showed a high PDI of 1.000, which suggests that the batch showed inhomogeneity in particle size. Usually, a PDI value of $<0.5$ is considered to be acceptable. A linear model was used to represent the factors affecting for PDI. Equation 2 shows the relationship between PDI and the coded factors.

$$
\begin{aligned}
\mathrm{PDI}= & 0.36+0.089 \mathrm{~A}+0.052 \mathrm{~B}+0.11 \mathrm{C} \\
& -0.004083 \mathrm{D}
\end{aligned}
$$

From Equation 2, we can observe that the effect of the four factors on PDI is comparatively lesser than that to particle size. The size of balls (A), the concentration of PVA (B), and the amount of ACF (C) were found to be directly related whereas the milling time (D) was inversely related to the PDI. The ANOVA analysis of the model with F-value of 3.00 indicates that it was significant. There was only $3.59 \%$ chance that the F-value could be due to noise. Prob $>$ F-value $<0.05$ indicates that the model generated is significant. The amount of ACF was found to affect the PDI $(P<0.05)$ significantly. As the amount of ACF was increased, there was a chance of inefficient particle size reduction, which could lead to non-uniform particle size distribution and result in high PDI, which would be in accordance with the results of particle size. The 3D plots depicting the effect of variables on PDI are presented in Figure 2A-F.

\section{Effect of independent variables on zeta potential}

Zeta potential is useful in interpreting the stability of nanosuspension. Generally, a zeta potential greater than +30 and $-30 \mathrm{mV}$ is considered to be stable. The higher the zeta, the greater will be the repulsion among the particles rendering the suspension stable. The zeta potential values of ACF nanocrystals ranged from -0.0725 to $-2.14 \mathrm{mV}$ as shown in Table 4. This low value suggests inefficient covering on the surface of the nanocrystals by PVA, resulting in unstable dispersion. When neutral polymers are used, a shift in the shear plane away from the surface was observed, resulting in lower values for zeta potential. ${ }^{45}$

\section{The polynomial regression equation generated for the coded factors is shown below

$$
\begin{aligned}
& +0.091 \mathrm{D}-0.14 \mathrm{AB}+0.66 \mathrm{AC}+0.051 \mathrm{CD} \\
& -0.085 \mathrm{~A}^{2}+0.33 \mathrm{~B}^{2}+0.31 \mathrm{C}^{2}+0.28 \mathrm{D}^{2}
\end{aligned}
$$$$
\text { Zeta potential }=-1.36+0.015 \mathrm{~A}-0.024 \mathrm{~B}+0.42 \mathrm{C}
$$

The quadratic model with F-value of 2.55 indicates that the model was significant with $3.32 \%$ chances that it could because of noise. In this case, the amount of ACF (C) and combined effect of size of balls and amount of ACF (AC) played a significant role in influencing the zeta potential of the dispersion $(P<0.05)$. The $3 \mathrm{D}$ plots shown in Figure $3 \mathrm{~A}-\mathrm{F}$ show the effect of variables on zeta potential. The increase in the amount of PVA was directly related to its zeta potential. The nonionic polymer PVA is reported to stabilize a variety of nanoparticle systems. With the increase in PVA concentration, absolute value of zeta potential was decreasing. However, it was going toward positive and stabilizing the system. As the amount of ACF increased, an increase in zeta potential moving toward zero was observed. The interactive effect of the size of balls together with the amount of ACF had a direct correlation with the zeta potential of the drug suspension. Keeping in mind the stability issues related to the nanocrystals in dispersion form on extended storage condition, and as per the TPP, the final intended dosage form was solid, the resulting formulation was converted to a dry powder by centrifugation. Hence the low zeta potential would probably not have significance in the current study.

\section{Optimization of the formulation}

The purpose of optimization was to obtain a product with desired CQAs with predefined responses. In our present study, the analysis was performed using Design-Expert software, and the solution was generated with a goal of attaining minimum particle size and PDI with maximum zeta potential. Figure 4 shows the optimum design space comprised of the yellow overlap region. The design space was very wide. Many solutions were suggested by the software based on the design space; however, the optimum formulation was selected based on the desirability value. The value near to 1.00 was chosen. The software suggested a solution with desirability value of 0.892 . It predicted that ACF nanocrystals with desired quality would be obtained by milling the 
A

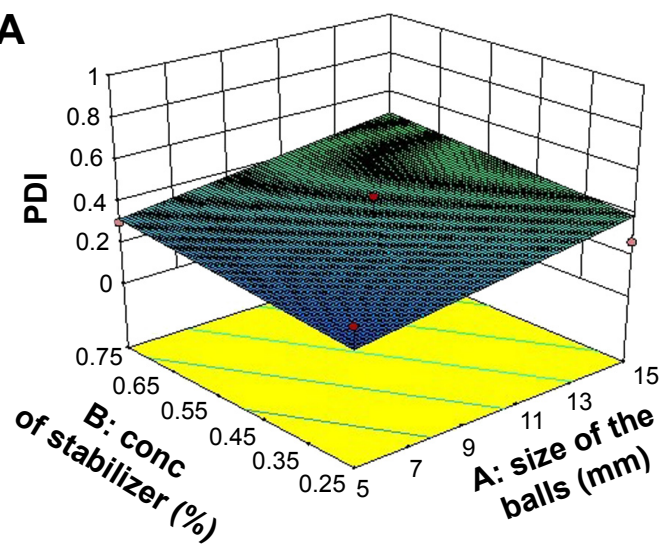

C

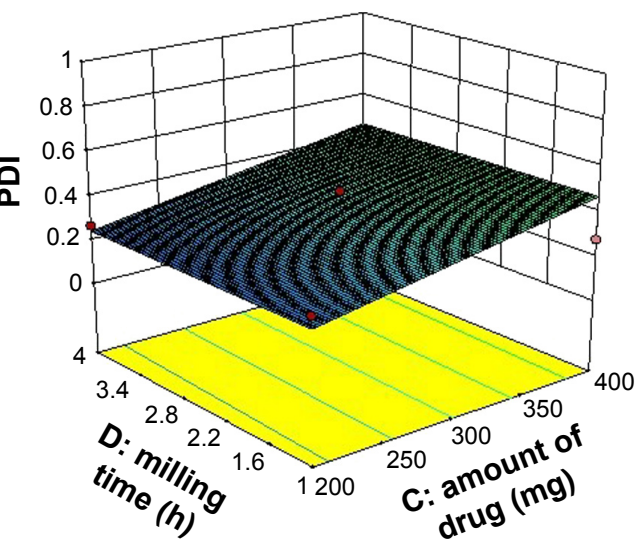

$\mathbf{E}$

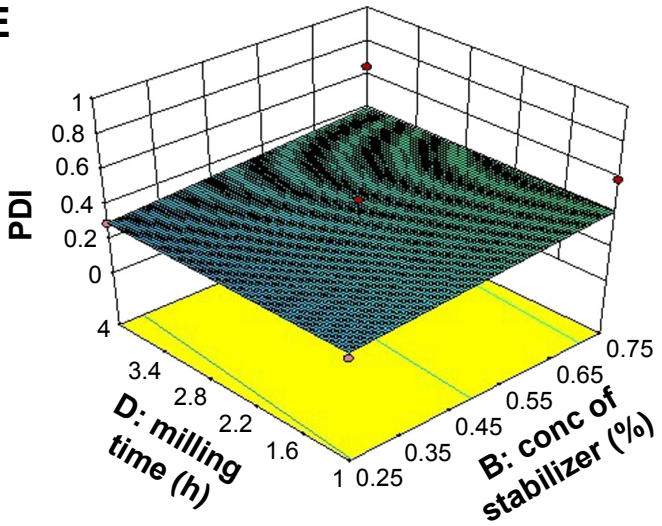

B

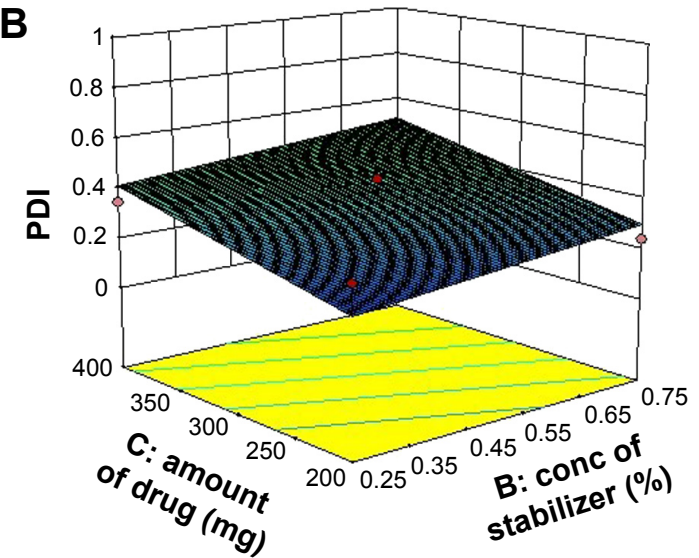

D

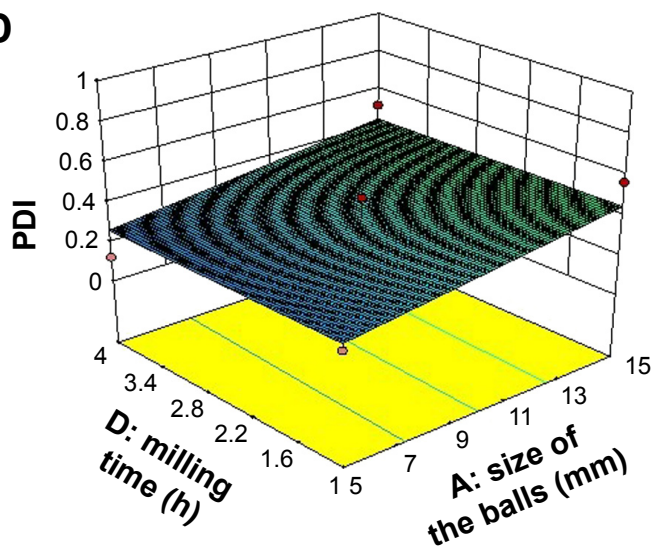

$\mathbf{F}$

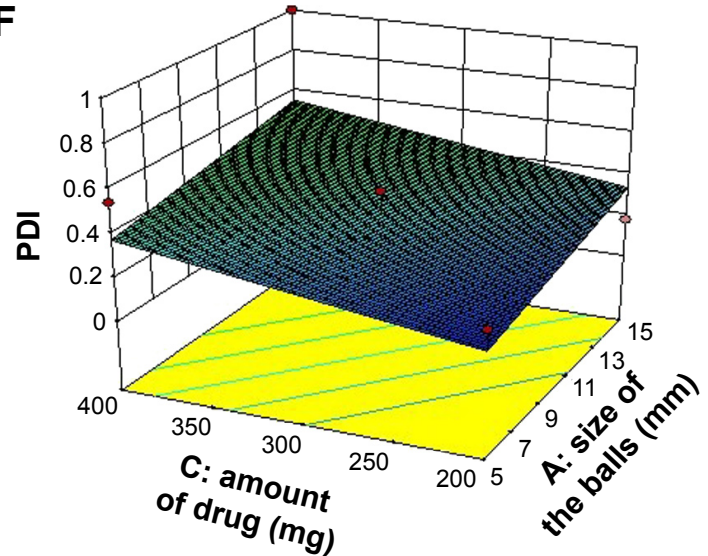

Figure 2 Three-dimensional plots showing the effect of independent variables on PDI.

Notes: (A) Effect of concentration of stabilizer and size of the balls on PDI; (B) Effect of concentration of stabilizer and amount of drug on PDI; (C) Effect of amount of drug and milling time on PDI; (D) Effect of milling time and size of the balls on PDI; (E) Effect of milling time and concentration of stabilizer on PDI; (F) Effect of amount of drug and size of the balls on PDI.

Abbreviations: conc, concentration; PDI, polydispersity index.

dispersion containing $200 \mathrm{mg} \mathrm{ACF}(\mathrm{C})$ in $0.25 \%$ PVA (B) solution for $4 \mathrm{~h}$ (D) using balls of $5 \mathrm{~mm}$ (A). A laboratory experiment with the predicted solution was performed, and the CQAs were evaluated to validate the procedure. The results of the predicted and obtained results are shown in Table 5 . The percentage error was found to be low $(<5 \%)$ indicating that the results obtained were considered to have a strong correlation with the software-generated results. The low percentage error can also be an indicator that the formulation developed with the optimized CMAs and CPPs may yield reproducible results with less variation in the CQAs of the product. 
A



C

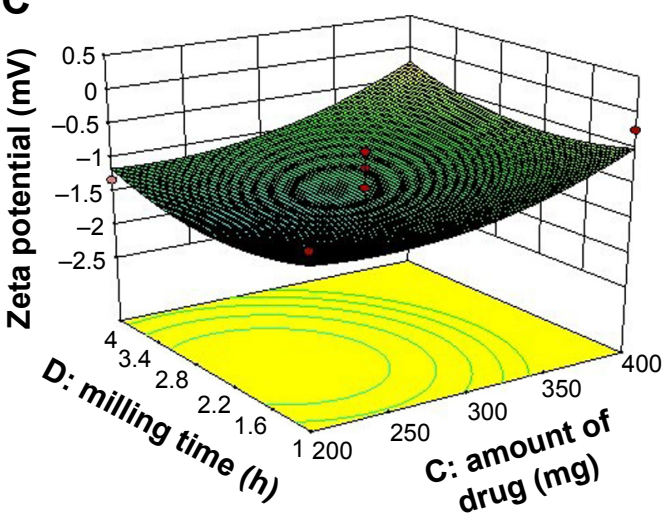

$\mathbf{E}$

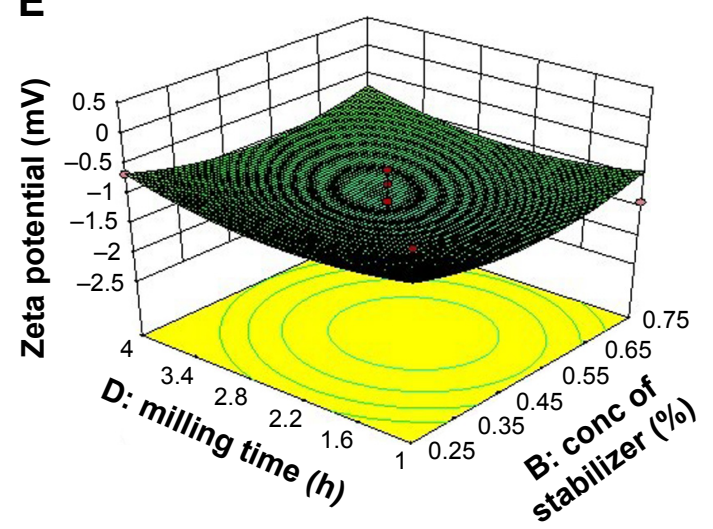

B

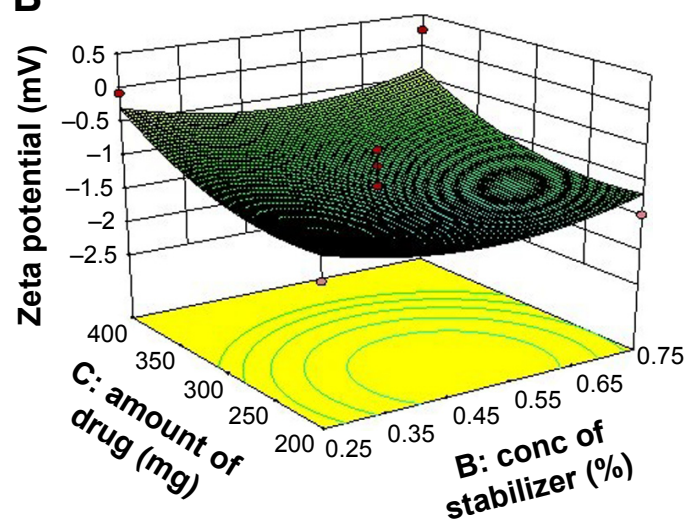

D



$\mathbf{F}$

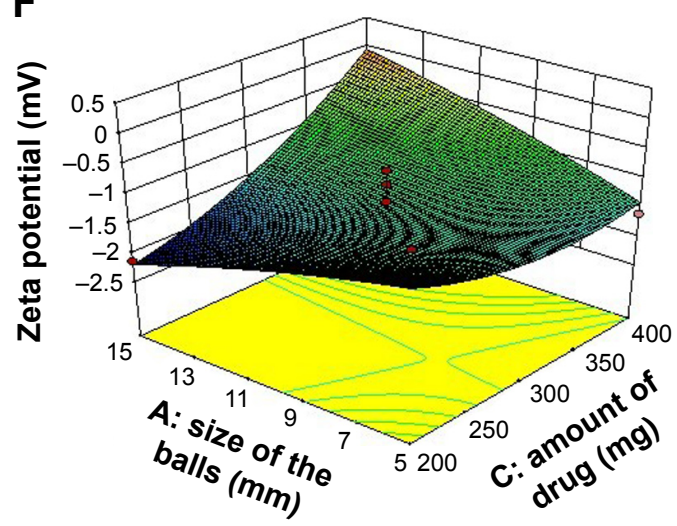

Figure 3 Three-dimensional plots showing the effect of independent variables on zeta potential.

Notes: (A) Effect of concentration of stabilizer and size of the balls on zeta potential; (B) Effect of concentration of stabilizer and amount of drug on zeta potential; (C) Effect of amount of drug and milling time on zeta potential; (D) Effect of milling time and size of the balls on zeta potential; (E) Effect of milling time and concentration of stabilizer on zeta potential; (F) Effect of amount of drug and size of the balls on zeta potential.

Abbreviation: conc, concentration.

\section{Characterization of the nanocrystals}

\section{Solid-state characterization}

A slight reduction in peak intensity but not a significant one could be appreciated from the XRD of ACF nanocrystals when compared with that of unmilled ACF. The characteristic peaks for ACF nanocrystals were found at the same $2 \theta$ value as that of unmilled ACF. This shows that the crystallinity of the ACF was not affected to a greater extent after the milling process. Reports suggest that polymeric stabilizers do not alter the crystal structure of drug particle that matches the obtained results where PVA was used as stabilizer. ${ }^{49}$ Figure $5 \mathrm{~A}$ and B shows the XRD pattern of unmilled powder and the nanocrystals.

\section{Thermal properties}

DSC thermograms of pure ACF (a) showed a typical endothermic peak at $156.31^{\circ} \mathrm{C}$ with an enthalpy of $-177.88 \mathrm{~J} / \mathrm{g}$. The physical mixture of ACF and PVA (1:1 ratio) gave a peak at $155.82^{\circ} \mathrm{C}$, and the nanocrystals of ACF showed a peak at 

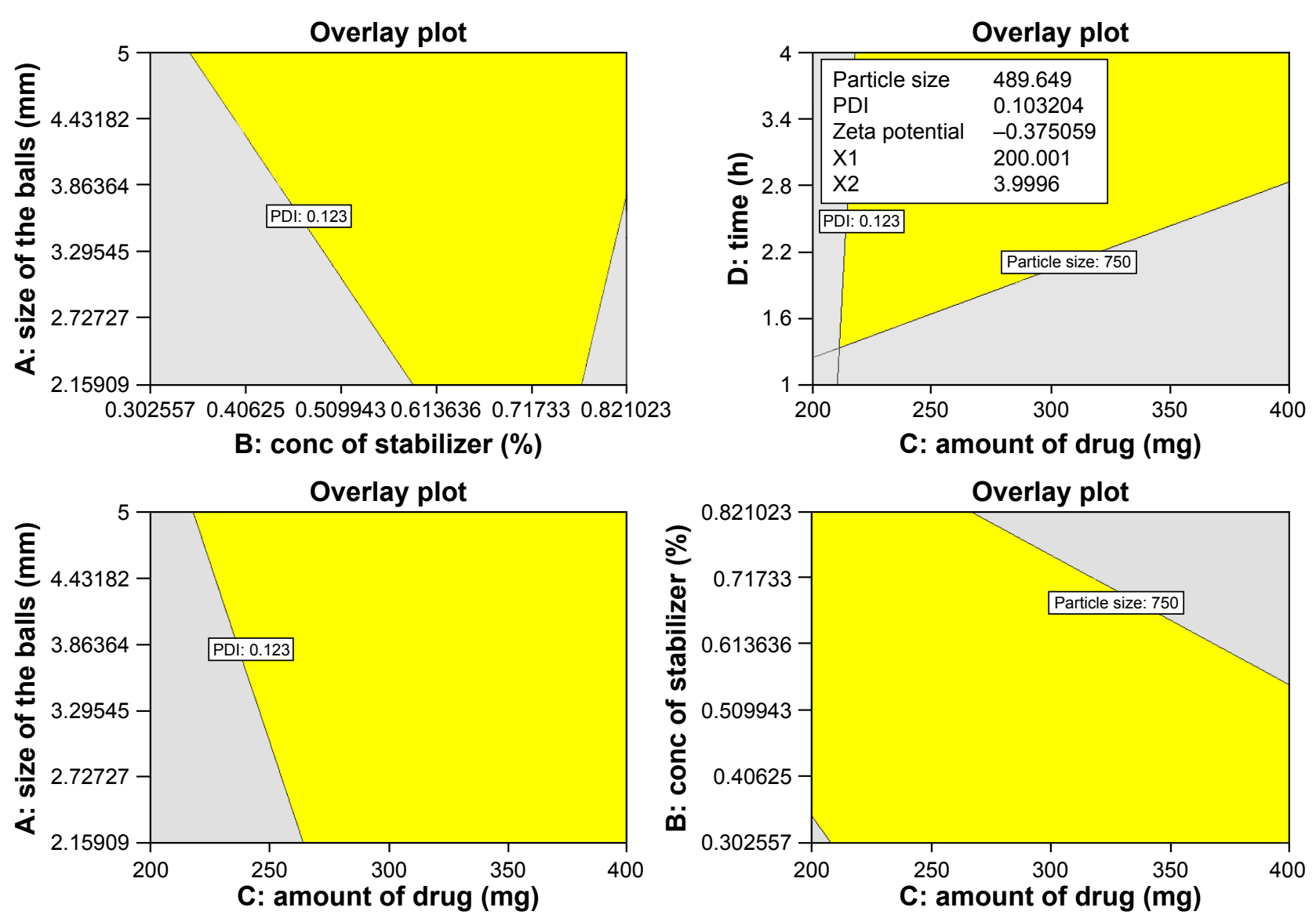

Figure 4 Design space of ACF nanocrystals comprised of the overlap region of ranges for the different critical quality attributes. Abbreviations: ACF, aceclofenac; PDI, polydispersity index.

$155.71^{\circ} \mathrm{C}$, which corresponds to the melting point of $\mathrm{ACF}$ and an enthalpy of $-113.12 \mathrm{~J} / \mathrm{g}$ indicating slightly reduced crystallinity. ${ }^{50-52}$ The results show the absence of any interaction between the drug and stabilizer PVA (Figure 6).

\section{Particle morphology}

The surface morphology of the nanocrystals was analyzed by scanning electron microscopy (SEM) studies. SEM images of unmilled ACF and nanocrystals are shown in Figure 7. Unmilled ACF was observed to be discrete in nature with smooth surface and crystalline in appearance. The surface texture of ACF nanocrystal particles was rough with much abrasiveness and disorderliness compared with unmilled ACF. The SEM results resemble those observed in some studies, which showed that milling altered the surface roughness and shape of particles. ${ }^{38}$

\section{Saturation solubility studies of nanocrystal formulation}

The saturation solubility of the pure drug and nanocrystals of $\mathrm{ACF}$ is shown in Figure 8. The figure indicates that there was a profound increase in the solubility of nanocrystals compared with that of pure drug. The solubility of pure ACF and nanocrystals of ACF in water was found to be $0.02 \pm 0.0013$ and $0.0399 \pm 0.0024 \mathrm{mg} / \mathrm{mL}$, respectively. In $0.1 \mathrm{~N} \mathrm{HCl}$, the solubility was found to be $0.0344 \pm 0.0026 \mathrm{mg} / \mathrm{mL}$ for pure ACF and $0.0569 \pm 0.003 \mathrm{mg} / \mathrm{mL}$ for ACF nanocrystals. This increase in solubility could be attributed to the reduction in

Table 5 Comparative values for observed and predicted results

\begin{tabular}{|c|c|c|c|c|c|c|c|}
\hline \multirow[t]{2}{*}{ Responses } & \multicolumn{4}{|c|}{ CMAs and CPPs } & \multicolumn{3}{|l|}{ CQAs } \\
\hline & $A(\mathrm{~mm})$ & B (\%) & C (mg) & D (h) & $\mathbf{Y}_{1}(\mathrm{~nm})$ & $\mathbf{Y}_{2}$ & $\mathbf{Y}_{3}(\mathrm{mV})$ \\
\hline Software-predicted results & 5.0 & 0.25 & 200 & 4 & 489.6 & 0.103 & -0.375 \\
\hline Obtained results & 5.0 & 0.25 & 200 & 4 & $484.7 \pm 54.12$ & $0.108 \pm 0.009$ & $-0.380 \pm 0.045$ \\
\hline Error* (\%) & - & - & - & - & 1.00 & -4.85 & -1.33 \\
\hline
\end{tabular}

Note: $*$ Error $=($ software predicted results - obtained results $) /$ software predicted results $\times 100$.

Abbreviations: CMAs, critical material attributes; CPPs, critical process parameters; CQAs, critical quality attributes. 
A

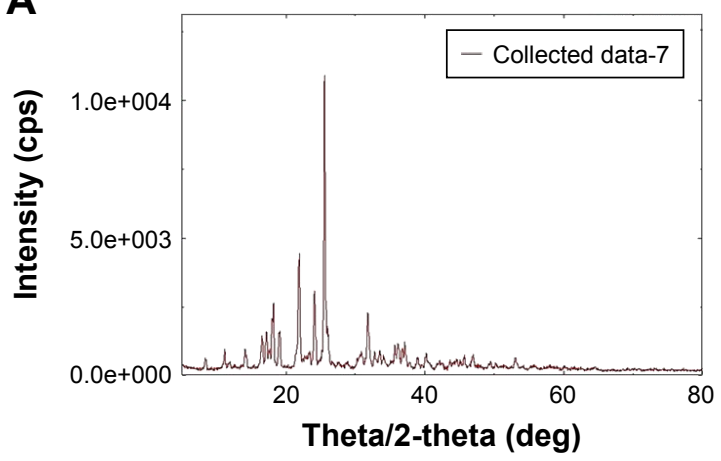

B

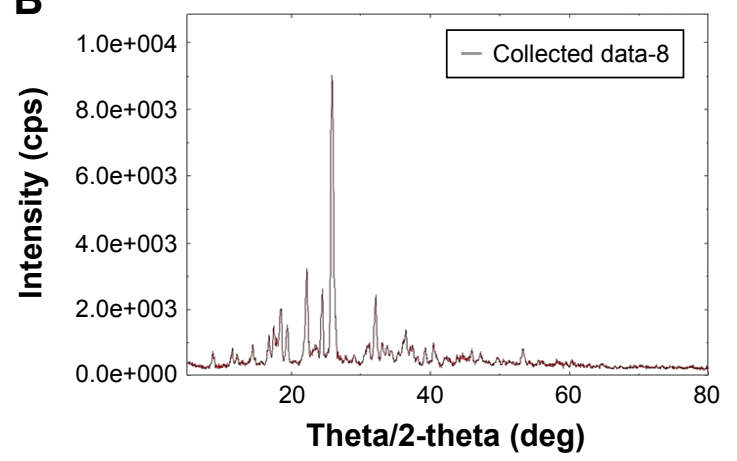

Figure 5 X-ray diffraction patterns for (A) pure unmilled ACF and (B) ACF nanocrystals. Abbreviation: ACF, aceclofenac.

particle size, leading to increase in the surface area and thus improved solubility as per Ostwald-Freundlich equation. ${ }^{53}$ The increased wettability owing to the presence of surface coating of PVA around the hydrophobic surface of ACF nanocrystals could also be a possible reason for the improvement in the solubility. ${ }^{54}$

\section{In vitro release studies}

The in vitro drug release profile of ACF nanocrystals showed an improvement in the drug release at the end of $2 \mathrm{~h}$, that is, $100.07 \% \pm 1.38 \%$, whereas the pure drug showed a release of around $47.66 \% \pm 4.53 \%$ in $0.1 \mathrm{~N} \mathrm{HCl}$ (Figure 9). This 2.19-fold increase in dissolution profile of the drug may be due to decrease in the particle size and high surface area, thus an improved dissolution of the drug as per NoyesWhitney equation. ${ }^{14}$ This could be speculated to be due to the decrease in diffusion layer thickness and hence an increase in concentration gradient, leading to increase in dissolution velocity. The high surface-to-volume ratio of nanoparticles also aids in the hydration and hence enhances the dissolution velocity. ${ }^{21}$ Presence of layer of PVA around the nanocrystals enhances the wettability of the poorly soluble drug and contributes to improved dissolution rate. The increased saturation solubility of the ACF nanocrystals also supports this high dissolution velocity of the nanocrystals.

\section{Pharmacokinetic studies}

Pharmacokinetic studies of the ACF nanocrystals in rats echoed similar results as that of in vitro studies. The plasma concentration-time profiles following single oral administration $(10 \mathrm{mg} / \mathrm{kg})$ of ACF nanocrystals and pure ACF are depicted in Figure 10. The pharmacokinetic parameters are tabulated in Table 6 . The results showed a significant increase in $\mathrm{C}_{\text {max }}$ of the ACF nanocrystals compared with that of pure ACF showing good oral absorption. ACF nanocrystals demonstrated significant high AUC compared with that of pure drug showing higher bioavailability of drug from the formulation. The increase in both $\mathrm{C}_{\max }$ and AUC could be due to increased rate and extent of absorption of nanocrystals due to higher dissolution velocity. This suggests that the

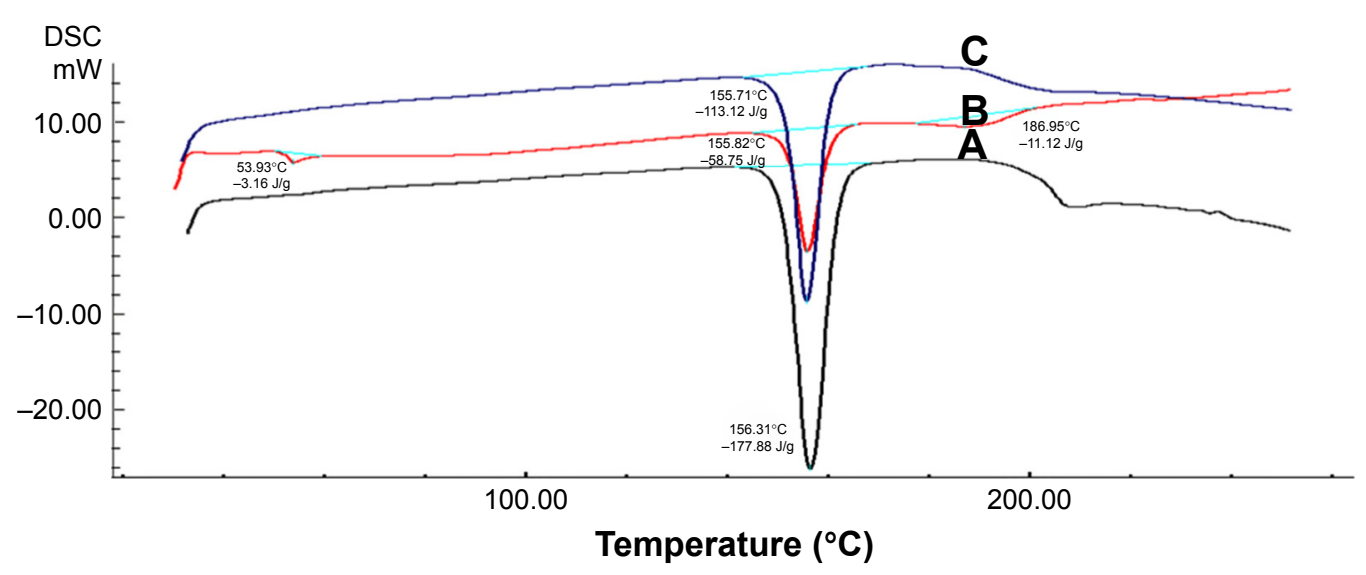

Figure 6 Differential scanning calorimetric (DSC) thermograms for (A) unmilled ACF (B) physical mixture of unmilled ACF + PVA and (C) ACF nanocrystals. Abbreviations: ACF, aceclofenac; DSC, differential scanning calorimetric; PVA, polyvinyl alcohol. 

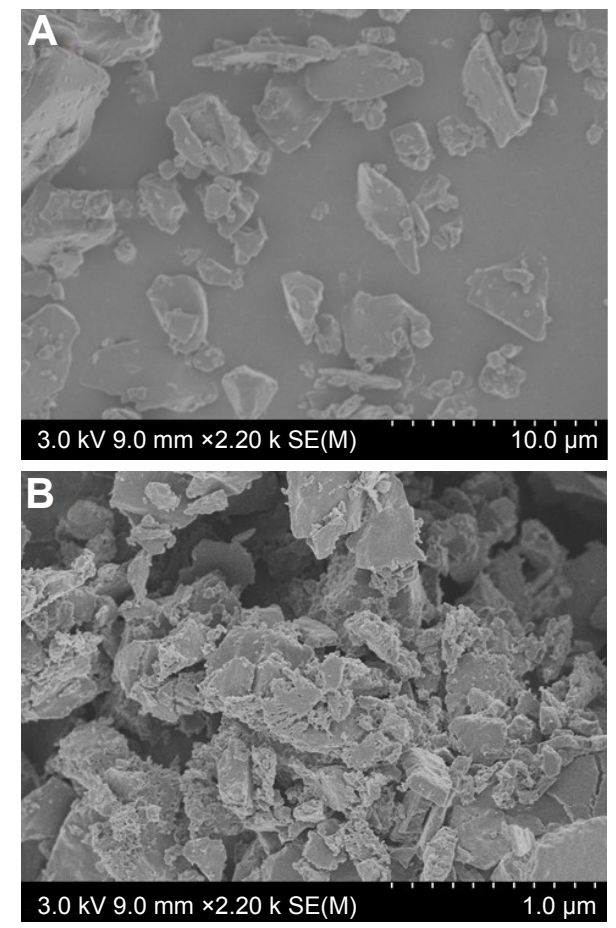

Figure 7 Scanning electron microscopy images of (A) unmilled ACF (B) ACF nanocrystals.

Abbreviation: ACF, aceclofenac.

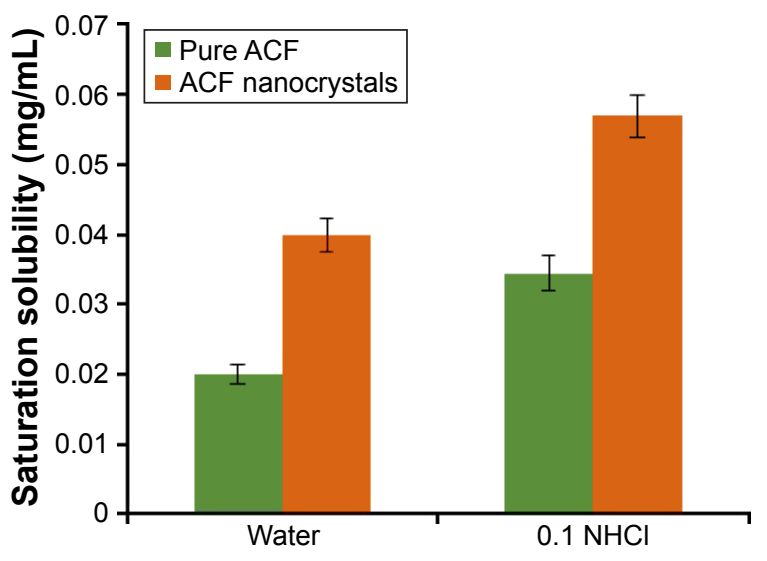

Figure 8 Saturation solubility studies of pure ACF and ACF nanocrystals. Abbreviation: ACF, aceclofenac.

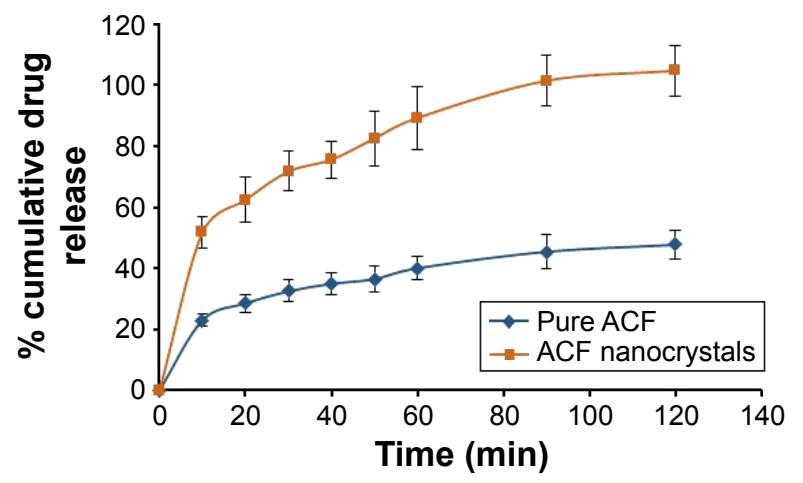

Figure 9 In vitro release profile of pure ACF and ACF nanocrystals. Abbreviation: ACF, aceclofenac.



Figure I0 Plasma concentration-time profile for pure ACF and ACF nanocrystals. Abbreviation: ACF, aceclofenac.

ACF nanocrystals can be used to reduce the dose of ACF. There was no significat difference in mean residential time, elimination half life $\left(\mathrm{t}_{1 / 2}\right)$, and elimination rate constant $(\mathrm{Ke})$ between the groups. Student's $t$-test results indicated that there was a significant statistical difference $(P<0.05)$ in the $\mathrm{C}_{\max }$ and $\mathrm{AUC}$ of the developed nanocrystals when compared with that of pure ACF.

\section{Stability studies}

Particle size and solubility were determined to ensure that the characteristics of the formulation remain unchanged throughout its shelf life. No significant difference was observed in the samples. The particle size at the end of 90 days was found to $512.5 \pm 49.38 \mathrm{~nm}$. The solubility of ACF nanocrystals in water and $0.1 \mathrm{~N} \mathrm{HCl}$ was found to be $0.0302 \pm 0.0029 \mathrm{mg} / \mathrm{mL}$ and $0.0528 \pm 0.0057 \mathrm{mg} / \mathrm{mL}$, respectively. The results revealed that the ACF nanocrystals were found to be stable under the specified conditions throughout their shelf life.

\section{Conclusion}

The present study illustrates the efficiency of particle size reduction in improving the solubility and thus the bioavailability of ACF by top-down approach. The CQAs and

Table 6 Pharmacokinetic parameters for pure ACF and ACF nanocrystals

\begin{tabular}{lll}
\hline Parameters & Pure ACF & ACF nanocrystals \\
\hline $\mathrm{C}_{\max }(\mu \mathrm{g} / \mathrm{mL})$ & $1.96 \pm 0.17$ & $3.75 \pm 0.28^{\mathrm{a}}$ \\
$\mathrm{T}_{\max }(\mathrm{h})$ & $1.00 \pm 0.25$ & $1.00 \pm 0.25$ \\
$\mathrm{t}_{1 / 2}(\mathrm{~h})$ & $3.42 \pm 0.15$ & $3.27 \pm 0.10$ \\
$\mathrm{AUC}$ & $5.8 \pm 0.87$ & $9.0 \pm 1.00^{\mathrm{a}}$ \\
$\mathrm{MRT}(\mathrm{h})$ & $4.30 \pm 0.95$ & $4.00 \pm 0.69$ \\
$\mathrm{~K}_{\mathrm{e}}\left(\mathrm{h}^{-1}\right)$ & $0.202 \pm 0.001$ & $0.267 \pm 0.0005$ \\
\hline
\end{tabular}

Notes: All values are expressed as mean $\pm S D, n=3$; a significantly different at $95 \%$ confidence interval.

Abbreviations: ACF, aceclofenac; AUC, area under the curve; $C_{\text {max }}$ maximum plasma concentration; $\mathrm{K}_{\mathrm{e}}$, elimination rate constant; MRT, mean residential time; $\mathrm{T}_{\text {max }}$, time for maximum plasma concentration; $\mathrm{t}_{1 / 2}$, elimination half life. 
CPPs were identified and the formulation was optimized at 3 levels and 4 factors using BBD. The optimum formulation was the one containing $0.25 \%$ PVA and $200 \mathrm{mg}$ of ACF which was milled for $4 \mathrm{~h}$ using balls of size $5 \mathrm{~mm}$ to obtain minimum particle size of $484.7 \pm 54.12 \mathrm{~nm}$ and PDI of $0.108 \pm 0.009$. The low percentage error confirms the agreement between the theoretical and practical data. Further, the ACF nanocrystals showed an improved solubility in water and $0.1 \mathrm{~N} \mathrm{HCl}$, which was supported by the increased dissolution velocity in in vitro release studies. The increase in the solubility of ACF was mainly due to particle size reduction rather than amorphization as the ACF nanocrystals showed crystalline nature evident from the solid-state characterization results. The pharmacokinetic data demonstrated an improved bioavailability and absorption of ACF, which supported the results obtained by in vitro studies. On the basis of the results obtained, it can be concluded that formulation of ACF nanocrystals by ball milling combined with QbD approach can help to reduce the dose, cost and ensure quality and safety of the product. The developed ACF nanocrystals could be exploited as a possible alternative to its currently available dosage forms.

\section{Acknowledgments}

The authors are thankful to Manipal University for providing the infrastructure facilities and Department of Biotechnology, New Delhi, India, for providing the financial support by a grant (BT/Bio-CARe/03/9943/2013-14), for carrying out this research work.

\section{Disclosure}

The authors report no conflicts of interest in this work.

\section{References}

1. Ku MS, Dulin W. A biopharmaceutical classification-based Right-FirstTime formulation approach to reduce human pharmacokinetic variability and project cycle time from First-In-Human to clinical Proof-Of-Concept. Pharm Dev Technol. 2012;17(3):285-302.

2. Kalepu S, Nekkanti V. Insoluble drug delivery strategies: review of recent advances and business prospects. Acta Pharm Sin B. 2015;5(5): 442-453.

3. Meka AK, Pola S, Tupally KR, Abbaraju PL. Development, evaluation and characterization of surface solid dispersion for solubility and dissolution enhancement of Irbesartan. Int J Drug Dev Res. 2012;4(1): 263-273.

4. Thirupathaiah A, Sunder RS. Formulation and evaluation of simvastatin solid dispersions by solvent evaporation method. Res J Pharm Biol Chem. 2016;7(4):2516-2528.

5. Sanphui P, Devi VK, Clara D, Malviya N, Ganguly S, Desiraju GR. Cocrystals of hydrochlorothiazide: Solubility and diffusion/permeability enhancements through drug-coformer interactions. Mol Pharm. 2015; 12(5):1615-1622.

6. Good DJ, Naír RH. Solubility advantage of pharmaceutical cocrystals. Cryst Growth Des. 2009;9(5):2252-2264.
7. Darekar T, Aithal KS, Shirodkar R, Kumar L, Attari Z, Lewis S. Characterization and in vivo evaluation of lacidipine inclusion complexes with $\beta$-cyclodextrin and its derivatives. J Incl Phenom Macrocycl Chem. 2016;84(3-4):225-235.

8. Jafar M, Ali S, Ghonaim HM. Improved solubility and dissolution rate of ketoprofen by beta cyclodextrin ternary complexes incorporating hydrophilic polymers. Int J Drug Deliv Technol. 2017;7(1):45-51.

9. Blagden N, de Matas M, Gavan PT, York P. Crystal engineering of active pharmaceutical ingredients to improve solubility and dissolution rates. Adv Drug Deliv Rev. 2007;59(7):617-630.

10. Li HY, Pan TT, Cui Y, et al. Improved oral bioavailability of poorly water-soluble glimepiride by utilizing microemulsion technique. Int $J$ Nanomedicine. 2016;11:3777-3788.

11. Narayan R, Attari Z, Sreenivasa Reddy M, Koteshwara KB. Enhanced solubility and bioavailability of pioglitazone nanosuspension. $A d v S c i$ Lett. 2016;22(4):987-994.

12. Kamble RN, Mehta PP, Kumar A. Efavirenz self-nano-emulsifying drug delivery system: in vitro and in vivo evaluation. AAPS PharmSciTech. 2016;17(5):1240-1247.

13. Bandi S, Sanka K, Bakshi V. Enhanced oral delivery of risperidone through a novel self-nanoemulsifying powder (SNEP) formulations: in-vitro and ex-vivo assessment. J Microencapsul. 2016;33(6): 544-553.

14. Tan Y, Yang Z, Peng X, et al. A novel bottom-up process to produce nanoparticles containing protein and peptide for suspension in hydrofluoroalkane propellants. Int J Pharm. 2011;413(1-2):167-173.

15. Junyaprasert VB, Morakul B. Nanocrystals for enhancement of oral bioavailability of poorly water-soluble drugs. Asian J Pharm Sci. 2015; 10(1):13-23.

16. Ye X, Patil H, Feng X, et al. Conjugation of hot-melt extrusion with high-pressure homogenization: a novel method of continuously preparing nanocrystal solid dispersions. AAPS PharmSciTech. 2016;17(1):78-88.

17. Raghava Srivalli KM, Mishra B. Drug nanocrystals: a way toward scale-up. Saudi Pharm J. 2016;24(4):386-404.

18. Möschwitzer JP. Drug nanocrystals in the commercial pharmaceutical development process. Int J Pharm. 2013;453(1):142-156.

19. Junghanns JU, Müller RH. Nanocrystal technology, drug delivery and clinical applications. Intl J Nanomedicine. 2008;3(3):295-309.

20. Van Eerdenbrugh B, Vermant J, Martens JA, et al. A screening study of surface stabilization during the production of drug nanocrystals. J Pharm Sci. 2009;98(6):2091-2103.

21. Elsayed I, Abdelbary AA, Elshafeey AH. Nanosizing of a poorly soluble drug: technique optimization, factorial analysis, and pharmacokinetic study in healthy human volunteers. Int J Nanomedicine. 2014; 9(1):2943-2953.

22. Van Eerdenbrugh B, Van den Mooter G, Augustijns P. Top-down production of drug nanocrystals: nanosuspension stabilization, miniaturization and transformation into solid products. Int J Pharm. 2008; 364(1):64-75.

23. Patravale VB, Date AA, Kulkarni RM. Nanosuspensions: a promising drug delivery strategy. J Pharm Pharmacol. 2004;56(7):827-840.

24. Akkus Arslan S, Tirnaksiz F. A nonsteroidal anti-inflammatory drug: Aceclofenac. FABAD J Pharm Sci. 2010;35:105-118.

25. Maulvi FA, Dalwadi SJ, Thakkar VT, Soni TG, Gohel MC, Gandhi TR. Improvement of dissolution rate of aceclofenac by solid dispersion technique. Powder Tech. 2011;207(1-3):47-54.

26. Dua K, Pabreja K, Ramana MV. Enhancement of dissolution behavior of aceclofenac by complexation with $\beta$-cyclodextrin-choline dichloride coprecipitate. J Disp Sci Tech. 2011;32(10):1477-1484.

27. Ranpise NS, Kulkarni NS, Mair PD, Ranade AN. Improvement of water solubility and in vitro dissolution rate of aceclofenac by complexation with $\beta$-cyclodextrin and hydroxypropyl- $\beta$-cyclodextrin. Pharm Dev Tech. 2010;15(1):64-70.

28. Mutalik S, Anju P, Manoj K, Usha AN. Enhancement of dissolution rate and bioavailability of aceclofenac: A chitosan-based solvent change approach. Int J Pharm. 2008;350(1-2):279-290. 
29. Park JJ, Meghani N, Choi JS, Lee BJ. Development and evaluation of decorated aceclofenac nanocrystals. Colloids Surf B Biointerfaces. 2016;143:206-212.

30. Pattnaik S, Swain K, Manaswini P, et al. Fabrication of aceclofenac nanocrystals for improved dissolution: Process optimization and physicochemical characterization. J Drug Deliv Sci Tech. 2015;29: 199-209.

31. Patnaik S, Aditha SK, Rattan T, Kamisetti V. Aceclofenac-soluplus nanocomposites for increased bioavailability. Soft Nanosci Letters. 2015; 5(2):13-20.

32. Xu X, Khan MA, Burgess DJ. A quality by design (QbD) case study on liposomes containing hydrophilic API: I. Formulation, processing design and risk assessment. Int J Pharm. 2011;419(1-2):52-59.

33. Patravale VB, Disouza JI, Rustomjee M. Pharmaceutical Product Development: Insights into Pharmaceutical Processes, Management and Regulatory Affairs. New York, NY: CRC Press, Taylor \& Francis Group; 2016.

34. Vo AQ, Feng X, Pimparade M, et al. Dual-mechanism gastroretentive drug delivery system loaded with an amorphous solid dispersion prepared by hot-melt extrusion. Eur J Pharm Sci. 2017;102:71-84.

35. Vo AQ, Feng X, Morott JT, et al. A novel floating controlled release drug delivery system prepared by hot-melt extrusion. Eur J Pharm Biopharm. 2016;98:108-121.

36. Masoumi HRF, Basri M, Samiun WS, Izadiyan Z, Lim CJ. Enhancement of encapsulation efficiency of nanoemulsion-containing aripiprazole for the treatment of schizophrenia using mixture experimental design. Int J Nanomedicine. 2015;10:6469-6471.

37. Usha AN, Mutalik S, Reddy MS, Ranjith AK, Kushtagi P, Udupa N. Preparation and, in vitro, preclinical and clinical studies of aceclofenac spherical agglomerates. Eur J Pharm Biopharm. 2008;70(2): 674-683.

38. Loh ZH, Samanta AK, Sia Heng PW. Overview of milling techniques for improving the solubility of poorly water-soluble drugs. Asian $J$ Pharml Sci. 2014;10(4):255-274.

39. Ramasamy T, Tran TH, Choi JY, et al. Layer-by-layer coated lipidpolymer hybrid nanoparticles designedfor use in anticancer drug delivery. Carbohydr Polym. 2014;102:653-661.

40. Ramasamy T, Ruttala HB, Chitrapriya N, et al. Engineering of cell microenvironment-responsive polypeptide nanovehicle co-encapsulating a synergistic combination of small molecules for effective chemotherapy in solid tumors. Acta Biomaterialia. 2017;48:131-143.

41. Ramasamy T, Ruttala HB, Kanu BG, et al. Smart chemistry-based nanosized drug delivery systems for systemic applications: a comprehensive review. J Control Rel. Epub 2017 May 1.
42. Li JK, Wang N, Wu XS. Poly(vinyl alcohol) nanoparticles prepared by freezing-thawing process for protein/peptide drug delivery. J Control Release. 1998;56(1-3):117-126.

43. Narayanan K, Subrahmanyam VM, Venkata Rao J. A fractional factorial design to study the effect of process variables on the preparation of hyaluronidase loaded PLGA nanoparticles. Enzyme Res. 2014;2014: 162962.

44. Sjöberg M, Bergström L, Larsson A, Sjöström E. The effect of polymer and surfactant adsorption on the colloidal stability and rheology of kaolin dispersions. Colloids Surf A Physicochem Eng Aspects. 1999; 159(1):197-208.

45. Rachmawati H, Rahma A, Al Shaal L, Müller RH, Keck CM. Destabilization mechanism of ionic surfactant on curcumin nanocrystal against electrolytes. Scientia Pharmaceutica. 2016;84(4):685-693.

46. Tefas LR, Tomuţă I, Achim M, Vlase L. Development and optimization of quercetin-loaded plga nanoparticles by experimental design. Clujul Medical. 2015;88(2):214-223.

47. Sharma N, Madan P, Lin S. Effect of process and formulation variables on the preparation of parenteral paclitaxel-loaded biodegradable polymeric nanoparticles: a co-surfactant study. Asian J Pharm Sci. 2016; 11(3):404-416.

48. Shin H, Lee S, Suk Jung H, Kim JB. Effect of ball size and powder loading on the milling efficiency of a laboratory-scale wet ball mill. Ceramics Int. 2013;39(8):8963-8968.

49. Peltonen L, Hirvonen J. Pharmaceutical nanocrystals by nanomilling: Critical process parameters, particle fracturing and stabilization methods. J Pharm Pharmacol. 2010;62(11):1569-1579.

50. Paradkar AR, Pawar AP, Chordiya JK, Patil VB, Ketkar AR. Spherical crystallization of celecoxib. Drug Dev Ind Pharm. 2002;28(10): 1213-1220.

51. Cirri M, Maestrelli F, Furlanetto S, Mura P. Solid-state characterization of glyburide-cyclodextrin co-ground products. J Thermal Analysis Calorimetry. 2004;77(2):413-422.

52. Corti G, Maestrelli F, Cirri M, Mura P, Zerrouk N. Dissolution and permeation properties of naproxen from solid-state systems with chitosan. Drug Deliv. 2008;15(5):303-312.

53. Khadka P, Ro J, Kim H, et al. Pharmaceutical particle technologies: an approach to improve drug solubility, dissolution and bioavailability. Asian J Pharm Sci. 2014;9(6):304-316.

54. Jain S, Sharma JM, Jain AK, Mahajan RR. Surface-stabilized lopinavir nanoparticles enhance oral bioavailability without coadministration of ritonavir. Nanomedicine (Lond). 2013;8(10):1639-1655.
International Journal of Nanomedicine

\section{Publish your work in this journal}

The International Journal of Nanomedicine is an international, peerreviewed journal focusing on the application of nanotechnology in diagnostics, therapeutics, and drug delivery systems throughout the biomedical field. This journal is indexed on PubMed Central, MedLine, CAS, SciSearch $®$, Current Contents $\AA /$ Clinical Medicine,

\section{Dovepress}

Journal Citation Reports/Science Edition, EMBase, Scopus and the Elsevier Bibliographic databases. The manuscript management system is completely online and includes a very quick and fair peer-review system, which is all easy to use. Visit http://www.dovepress.com/ testimonials.php to read real quotes from published authors. 